\title{
Decreased VEGF Level Is Associated with Elevated Ferritin Concentration in Bronchoalveolar Lavage Fluid of Children with Interstitial Lung Diseases
}

\author{
Ágnes Papp ${ }^{a} \quad Z^{2}$ solt Bene ${ }^{a} \quad$ Imre Gáspár ${ }^{a} \quad$ Béla Nagy Jr. ${ }^{b} \quad$ László Kádár ${ }^{c}$ \\ Tivadar Márialigetic Andrea Bánfid ${ }^{d}$ György Baktaid György Balla ${ }^{a}$ Béla Nagya \\ Departments of a Pediatrics and ${ }^{b}$ Laboratory Medicine, Clinical Center, University of Debrecen, Debrecen, \\ 'Department of Pediatrics, County Hospital for Pulmonology, Törökbálint, and '`Svábhegy' Health Service Ltd. for \\ Allergy, Immunology and Pulmonary Diseases, Budapest, Hungary
}

\section{Key Words}

Vascular endothelial growth factor · Ferritin .

Bronchoalveolar lavage $\cdot$ Interstitial lung diseases $\cdot$ Children

\begin{abstract}
Background: A decreased level of vascular endothelial growth factor (VEGF) was previously described in bronchoalveolar lavage fluid (BALF) of adults with interstitial lung diseases (ILD) due to bronchial epithelial cell apoptosis and its proteolytic degradation. Elevated intrapulmonary ferritin was produced by alveolar cells that promoted oxidative injury in such patients. Objectives: In this study, we analyzed the concentrations of VEGF and ferritin in BALF samples of ILD children and studied the relationship between their levels and the degree of inflammation. Methods: BALF and serum concentration of VEGF as well as ferritin and albumin in BALF samples were measured using enzyme-linked immunosorbent assay in children with idiopathic interstitial pneumonia $(n=16)$, hypersensitivity pneumonitis $(n=11)$ and idiopathic pulmonary hemosiderosis $(n=3)$. Twenty-four age- and gender-matched subjects with suspicious foreign body aspiration served as a control group. Results: VEGF per albumin levels in BALF were significantly decreased in ILD children compared to controls $(1,075[784-1,415] \mathrm{pg} / \mathrm{mg}$ albumin vs. $2,741[1,131-4,660] \mathrm{pg} / \mathrm{mg}$ albumin, $\mathrm{p}=0.0008)$.
\end{abstract}

These values showed a significant negative correlation with inflammatory markers of total immune cell count in BALF $(r=-0.411, p=0.002)$ and serum C-reactive protein $(r=-0.367$, $p=0.006$ ). Although serum VEGF was augmented in ILD children versus controls, no difference was observed among the ILD groups. In addition, BALF ferritin/albumin level (688 [188$1,571] \mathrm{ng} / \mathrm{mg}$ albumin vs. 256 [178-350] $\mathrm{ng} / \mathrm{mg}$ albumin, $\mathrm{p}=$ 0.022) was significantly higher than normal in ILD individuals, especially in idiopathic pulmonary hemosiderosis. Conclusion: Depressed VEGF and increased ferritin in BALF may reflect the severity of chronic pulmonary inflammation in altered respiratory epithelium of childhood ILD.

(c) 2015 S. Karger AG, Base

\section{Introduction}

Vascular endothelial growth factor (VEGF) was first identified in tumor-related ascites fluid, when hepatocarcinoma cells were shown to produce a protein for increasing vascular permeability to promote ascites fluid accumulation [1]. Apart from malignant conditions, VEGF is constitutively produced by normal epithelial cells [2], but it may be also generated by the response to variable inflammatory mediators such as IL- $1 \beta$ and TNF- $\alpha$. VEGF may be overexpressed by the injured epithelium $[2,3]$,

\section{KARGER 125}

C 2015 S. Karger AG, Base

0025-7931/15/0906-0443\$39.50/0

E-Mail karger@karger.com

www.karger.com/res
Béla Nagy, MD, PhD

Department of Pediatrics, Clinical Center

University of Debrecen

Nagyerdei körút 98, HU-4032 Debrecen (Hungary)

E-Mail bnagy@med.unideb.hu 
smooth muscle cells and neutrophils [4]. This cytokine results in increased vascular permeability and smooth muscle cell hypertrophy, but also stimulates the development of vessels by inducing the proliferation of endothelial cells $[2,5,6]$. In the early stage of acute lung injury due to hypoxia, alveolar macrophages and type II epithelial cells produce VEGF temporarily at an increased quantity, causing vascular leakage and interstitial edema [7]. However, during the development of acute respiratory distress syndrome (ARDS), damage of epithelial cells and release of proteases from neutrophils decrease the VEGF level in the alveolar compartment, while serum VEGF is elevated $[7,8]$. Later, VEGF concentrations may also increase again when lung tissue is recovering $[7,8]$. Abnormally high bronchoalveolar lavage fluid (BALF) VEGF played an essential role in the development of several acute and chronic inflammatory lung diseases in adults, such as asthma [9-11], acute eosinophilic pneumonia [12] and chronic bronchitis [13]. In contrast, decreased VEGF levels in BALF were measured in adults with idiopathic pulmonary fibrosis (IPF) compared to normal individuals [14-16]. There were several causes in the background of this alteration, such as lower production of VEGF because of bronchial epithelial cell apoptosis, its proteolytic degradation by proteases released from neutrophils, and a considerable shift of VEGF from BALF into the circulation [14, 15]. Consequently, increased VEGF concentration was measured in the serum of adults with IPF compared to healthy volunteers $[14,17,18]$. The analysis of VEGF in BALF or sera provides further evidence in the pathomechanism of distinct type of inflammatory pulmonary diseases and may reflect disease progression in adults $[7,17,18]$. However, no information is available on VEGF values in BALF in childhood interstitial lung diseases (ILD).

Ferritin is a multimeric protein with a very high capacity for storing iron, and its increased levels in BALF in response to inflammation were associated with impaired iron homeostasis and metal-catalyzed oxidative stress in several diseases, also in idiopathic pulmonary alveolar proteinosis [19]. Similarly, abnormal BALF iron concentration released from a high level of extracellular ferritin promoted oxidative injury, causing impaired local immune function in cystic fibrosis [20,21]. In a rat model, iron overload generated via inhalation resulted in persistent lung injury with severe inflammation at elevated BALF ferritin levels [22]. Hypoxia and severe intrapulmonary inflammation could induce further ferritin accumulation in the alveolar surface and its release from alveolar macrophages in pulmonary disorders [23]. However, it is still unknown how ferritin level is altered in BALF of ILD in children.
Bronchoalveolar lavage (BAL) is an established diagnostic tool in variable types of ILD that supports the clinical diagnosis not only in adults but also in children [2427]. The objective of this study was to analyze VEGF and ferritin levels in BALF samples in children with different types of ILD: hypersensitivity pneumonitis (HP), idiopathic interstitial pneumonia (IIP) and idiopathic pulmonary hemosiderosis (IPH). These results were adjusted to BALF albumin for the correction of recovered BALF content and compared to data measured in control individuals with suspected but finally not approved aspiration of foreign body by bronchoscope and without considerable inflammation in the lung. In addition, the BALF cell pattern was also characterized to improve diagnostic accuracy and to indicate the severity of inflammation [28]. Serum VEGF values were simultaneously measured in all study participants. We hypothesized that the albumin-related level of VEGF and that of ferritin with serum VEGF were altered in childhood ILD and correlated with the severity of intrapulmonary inflammation as useful biomarkers in these diseases.

\section{Patients and Methods}

Due to the relatively low incidence of ILD, patients were enrolled from January 2001 through December 2011 at three main national care centers of childhood lung diseases. The Regional and Institutional Ethics Committee of the University of Debrecen approved the trial (number: 3755-2012) in accordance with the Declaration of Helsinki. Written informed consent was obtained from the parent or legal guardian of each child before study recruitment.

\section{Patients}

During the study period, 47 children were admitted with suspicious physical signs and symptoms of ILD. Among them, 30 subjects (13 males, 17 females) were proved to have ILD. Eleven patients had HP with insidious onset, signs of progressive respiratory distress, mixed restrictive/obstructive pattern of lung function impairment and a history of exposure to organic antigens such as feathers and/or molds. All patients had evidence of serum precipitins against feather antigens. When using flow cytometry, lymphocytes were present in the following ratios (median [range]) regarding the total cell count: CD3-positive cells 68.2\% [49-83\%]; CD4 lymphocytes $28.3 \%$ [15-49\%] and CD8 cells 39.7\% [22-56\%] in BALF samples confirming the clinical diagnosis (data not shown). Sixteen children suffered from IIP with worsening lung function and deterioration of alveo-capillary function detected by dynamic inhalative lung scan as described previously [29]. These subjects were histopathologically classified as acute interstitial pneumonia $(\mathrm{n}=5)$, non-specific interstitial pneumonitis $(\mathrm{n}=7)$ or non-classified IIP $(\mathrm{n}=4)$ by open lung biopsy or video-assisted thoracoscopic surgery $[30,31]$. Finally, three subjects were diagnosed with IPH based on hemoptysis, bilateral bloody bronchial discharge by bronchoscopy and hemosiderin-laden macrophages 
of $>95 \%$ in BALF [32]. High-resolution computed tomography (HRCT) was used in all ILD patients for the diagnosis and to evaluate the severity of these diseases. BALF sampling was performed at the time of diagnosis, and no patient received systemic corticosteroid and/or immunosuppressive regimen before the BAL procedure. As controls, 24 patients (12 males, 12 females) were recruited; they were hospitalized because of suspected aspiration of foreign bodies that was not confirmed by bronchoscopy.

In addition, there were 17 subjects having no ILD who were eventually excluded from this investigation: 11 suffered from virusinduced interstitial pneumonitis, 2 from lymphoproliferative disease, 1 from Niemann-Pick disease [33], 2 from Langerhans cell histiocytosis [34] and 1 from pulmonary sarcoidosis (data not shown).

\section{BAL Procedure and Sample Handling}

BALF was sampled as previously described [26]. In brief, sterile isotonic sodium chloride solution at $37^{\circ} \mathrm{C}$ was instilled into the right middle or lower lobe in $20-\mathrm{ml}$ aliquots via a plastic catheter using a rigid tube bronchoscope (Karl Storz GmbH \& Co. KG, Tuttlingen, Germany) during general anesthesia. The total lavage volume was $4 \mathrm{ml} / \mathrm{kg}$ body weight and the fluid was immediately aspirated by gentle suction after each aliquot. The recovered lavage fluid volume was evaluated as a whole without discarding any aliquot. The recovered volume was considered as a representative sample if it exceed $50 \%$ of the instilled volume. Cellular analysis was performed immediately after the BAL procedure. The fluid was filtered through sterile nylon gauze and centrifuged at $800 \mathrm{~g}$ for $10 \mathrm{~min}$. The cells were resuspended in RPMI-1640 tissue culture medium (Sigma-Aldrich Co. Ltd., Dorset, England) containing 0.2\% bovine serum albumin. Differential cell counts were obtained from smears stained by MayGrünwald-Giemsa. A total cell count $<1.5 \times 10^{5} / \mathrm{ml}$ of the recovered fluid was considered normal [26]. The supernatant was stored at $-70^{\circ} \mathrm{C}$ until analysis. To avoid any bias, BALF cellularity was analyzed by two independent blinded investigators.

Measurement of VEGF, Ferritin and Albumin Concentrations

VEGF concentrations in BALF and serum samples were measured by commercially available quantitative sandwich enzymelinked immunosorbent assay (R\&D Systems, Minneapolis, Minn., USA) according to the manufacturer's protocol. Each sample was analyzed in duplicate. This VEGF assay predominantly binds to monomeric VEGF consisting of 165 amino acids. BALF ferritin and serum albumin levels were determined by an electrochemiluminescent immunoassay (Cobas e602, Roche, Mannheim, Germany). The upper detection level of ferritin was 2,000 pg/ml. BALF values of VEGF and ferritin were expressed in relation to albumin in $\mathrm{pg} / \mathrm{mg}$ and $\mathrm{ng} / \mathrm{mg}$, respectively, since we considered the degree of the dilution of the BALF samples during the procedure at the use of different amounts of lavage fluid at distinct ages. Albumin concentration in BALF samples was measured by the bromocresol green method (Sigma-Aldrich, St. Louis, Mo., USA), $<40 \mathrm{mg} / \mathrm{l}$ being considered normal.

\section{Statistical Analysis}

The Kolmogorov-Smirnov test was used for evaluation of the normality of the data. Results were expressed as median (range). Normally distributed parameters were analyzed by using twotailed Student's independent $t$ test. Non-parametric variables between two distinct treatment groups were compared using the Mann-Whitney $\mathrm{U}$ test. $\mathrm{p}$ values $<0.05$ were considered statistically significant. Correlations between different parameters were determined using Spearman's rank correlation. All analyses were performed using the SPSS Statistics software, version 19.0 (IBM Corp., Armonk, N.Y., USA).

\section{Results}

Demographic characteristics did not differ significantly between the entire ILD study group and the controls $(6.5[2-11]$ vs. $6.8[3-13]$ years, $\mathrm{p}=0.555)$ (table 1$)$. The case history was the longest in our IIP cohort (3.5 [1.55.0] months). Serum C-reactive protein (CRP) levels were significantly elevated in ILD children (in all ILD subgroups: 16 [2.0-35] vs. 2.0 [0.5-15] mg/l, p < 0.0001) compared to controls. Lung function test was performed in those aged $>6$ years, therefore, due to lack of this result in several children, median value [range] of forced vital capacity (FVC) and that of forced expiratory volume in $1 \mathrm{~s}$ ( $\mathrm{FEV}_{1}$; expressed in percent of the predicted values) were available only in the HP group (FVC: 61\% [4471.3\%]; $\mathrm{FEV}_{1}:$ 58.5\% [45-69.5\%]) (data not shown). Measurements of oxygen saturation at rest revealed normal values in the control group and a slight decrease in children with ILD. HRCT detected diffuse intrapulmonary abnormalities at various degrees, which were scored as follows: 1 = ground-glass attenuation, 2 = linear opacities, 3 = subpleural micronodules and $4=$ bilateral patchy consolidations (table 1). No honeycombing (HRCT score 5) was observed in any participant.

The total cell counts in BALF samples are summarized in table 2. Compared to the control group with normal BALF cytology, significantly increased total cell counts were measured in BALF samples of all ILD groups within a relatively homologue range $\left(0.95[0.57-1.3] \times 10^{5} / \mathrm{ml}\right.$ vs. 4.34 [2.97-4.68] $\times 10^{5} / \mathrm{ml}, \mathrm{p}<0.0001,4.52[2.7-6.73] \times$ $10^{5} / \mathrm{ml}, \mathrm{p}<0.0001$, and $3.75[3.35-5.1] \times 10^{5} / \mathrm{ml}, \mathrm{p}<$ 0.001 , respectively). Alveolar macrophages represented the largest group of cells in IPH samples (2.96 [2.51-4.14] $\times 10^{5} / \mathrm{ml}, \mathrm{p}<0.001 ; 79.3 \%$ of total cell count), while lymphocytes showing significantly increased count $(2.44$ [1.77-3.62] $\times 10^{5} / \mathrm{ml}, \mathrm{p}<0.0001 ; 63.9 \%$ of total cell count) were the most typical cells in HP. The level of neutrophils had the largest increment in the IIP group (1.25 [0.46$2.0] \times 10^{5} / \mathrm{ml}, \mathrm{p}<0.0001 ; 25.9 \%$ of total cell count) versus controls $\left(0.02[0-0.036] \times 10^{5} / \mathrm{ml}\right)($ table 2$)$.

After we had measured VEGF levels in BALF samples, these concentrations were normalized to their albumin levels. BALF albumin concentrations were elevated in all ILD children (IIP: 0.146 [0.114-0.210] mg/ml, p < 0.0001;
Altered Bronchoalveolar VEGF and

Ferritin in Children with ILD 
Table 1. Demographic parameters of all study populations

\begin{tabular}{|c|c|c|c|c|c|c|}
\hline Diagnosis & $\mathrm{M} / \mathrm{F}$ & $\begin{array}{l}\text { Age, } \\
\text { years }\end{array}$ & $\begin{array}{l}\text { CRP, } \\
\mathrm{mg} / \mathrm{l}\end{array}$ & $\begin{array}{l}\text { Oxygen } \\
\text { saturation }\end{array}$ & $\begin{array}{l}\text { HRCT } \\
\text { stage }\end{array}$ & $\begin{array}{l}\text { Length of } \\
\text { case history, } \\
\text { months }\end{array}$ \\
\hline $\begin{array}{l}\text { Controls } \\
(\mathrm{n}=24)\end{array}$ & $12 / 12$ & $6.5(2-11)$ & $2.0(0.5-15)$ & $95 \%(94-97 \%)$ & NA & NA \\
\hline $\begin{array}{l}\mathrm{HP} \\
(\mathrm{n}=11)\end{array}$ & $8 / 3$ & $9.0(5-13)$ & $12.0(2.0-21)$ & $91 \%(88-94 \%)$ & $\begin{array}{l}1 / 6 \\
2 / 5\end{array}$ & $2.0(1.5-3)$ \\
\hline $\begin{array}{l}\text { IIP } \\
(\mathrm{n}=16)\end{array}$ & $3 / 13$ & $4.5(3-16)$ & $21.3(3-35)$ & $93 \%(88-95 \%)$ & $\begin{array}{l}1 / 8 \\
2 / 7 \\
3 / 1\end{array}$ & $3.5(1.5-5)$ \\
\hline $\begin{array}{l}\text { IPH } \\
(n=3)\end{array}$ & $2 / 1$ & $4.0(3-9)$ & $14.0(12-23)$ & $90 \%(89-92 \%)$ & $\begin{array}{l}1 / 0 \\
2 / 2 \\
3 / 0 \\
4 / 1\end{array}$ & $3.0(2-3)$ \\
\hline
\end{tabular}

The number of patients is presented as $\mathrm{n}$; data are expressed as median (range). HRCT stage: $1=$ ground-glass attenuation; 2 = linear opacities; 3 = subpleural micronodules; 4 = bilateral patchy consolidations; results are expressed as stage/number of patients.

NA $=$ Not applicable.

Table 2. Cellular parameters of BALF samples obtained from various ILD children and controls

\begin{tabular}{lllll}
\hline Diagnosis & $\begin{array}{l}\text { Total cell count, } \\
\times 10^{5} / \mathrm{ml}\end{array}$ & $\begin{array}{l}\text { Macrophages, } \\
\times 10^{5} / \mathrm{ml}\end{array}$ & $\begin{array}{l}\text { Lymphocytes, } \\
\times 10^{5} / \mathrm{ml}\end{array}$ & $\begin{array}{l}\text { Neutrophils, } \\
\times 10^{5} / \mathrm{ml}\end{array}$ \\
\hline $\begin{array}{l}\text { Controls } \\
(\mathrm{n}=24)\end{array}$ & $0.95(0.57-1.3)$ & $0.73(0.46-1.07)$ & $0.08(0.046-0.15)$ & $0.02(0-0.036)$ \\
\hline $\begin{array}{l}\mathrm{HP} \\
(\mathrm{n}=11)\end{array}$ & $4.34(2.97-4.68)^{\mathrm{d}}$ & $1.1(0.75-2.12)^{\mathrm{a}}$ & $2.44(1.77-3.62)^{\mathrm{d}}$ & $0.13(0.079-0.21)^{\mathrm{c}}$ \\
\hline $\begin{array}{l}\text { IIP } \\
(\mathrm{n}=16)\end{array}$ & $4.52(2.7-6.73)^{\mathrm{d}}$ & $1.99(1.34-2.52)^{\mathrm{b}}$ & $1.15(0.50-2.0)^{\mathrm{b}}$ & $1.25(0.46-2.0)^{\mathrm{d}}$ \\
\hline $\begin{array}{l}\text { IPH } \\
(\mathrm{n}=3)\end{array}$ & $3.75(3.35-5.1)^{\mathrm{c}}$ & $2.96(2.51-4.14)^{\mathrm{c}}$ & $0.41(0.35-0.52)^{\mathrm{c}}$ & $0.38(0.37-0.48)^{\mathrm{d}}$ \\
\hline
\end{tabular}

Statistical significance was detected when comparing the data of ILD children to those of controls. The number of patients is presented as $\mathrm{n}$; data are expressed as median (range).

${ }^{\mathrm{a}} \mathrm{p}<0.05 ;{ }^{\mathrm{b}} \mathrm{p}<0.01 ;{ }^{\mathrm{c}} \mathrm{p}<0.001 ;{ }^{\mathrm{d}} \mathrm{p}<0.0001$.

HP: 0.115 [0.104-0.153] mg/ml, p < 0.001; IPH: 0.168 $[0.165-0.190] \mathrm{mg} / \mathrm{ml}, \mathrm{p}=0.005)$ compared to controls $(0.0253[0.018-0.046] \mathrm{mg} / \mathrm{ml})$ (data not shown). Accordingly, significantly decreased VEGF/albumin ratios were found in patients with HP $(957[826-1,102] \mathrm{pg} / \mathrm{mg}, \mathrm{p}=$ $0.019)$, IIP $(1,305[817-1,566] \mathrm{pg} / \mathrm{mg}, \mathrm{p}=0.016)$ and IPH (773 [697-1,168] pg/mg, $\mathrm{p}=0.015)$ compared to controls $(2,741[1,131-4,660] \mathrm{pg} / \mathrm{mg})$ (fig. 1a). In contrast, the median serum VEGF level was augmented in ILD children versus controls and statistically significantly increased in HP (309 [229-361] pg/ml, p = 0.023) and IPH (296 [266$298] \mathrm{pg} / \mathrm{ml}, \mathrm{p}=0.046)$. Additionally, these values were also markedly abnormal (255 [186-333] pg/ml, p = 0.124) in IIP (fig. 1b). However, there was no alteration in serum VEGF between the ILD subgroups.

We then determined BALF ferritin/albumin ratios, and as expected the most substantial increment was found in IPH $(11,926[10,657-12,113] \mathrm{ng} / \mathrm{mg})$. There was also a 

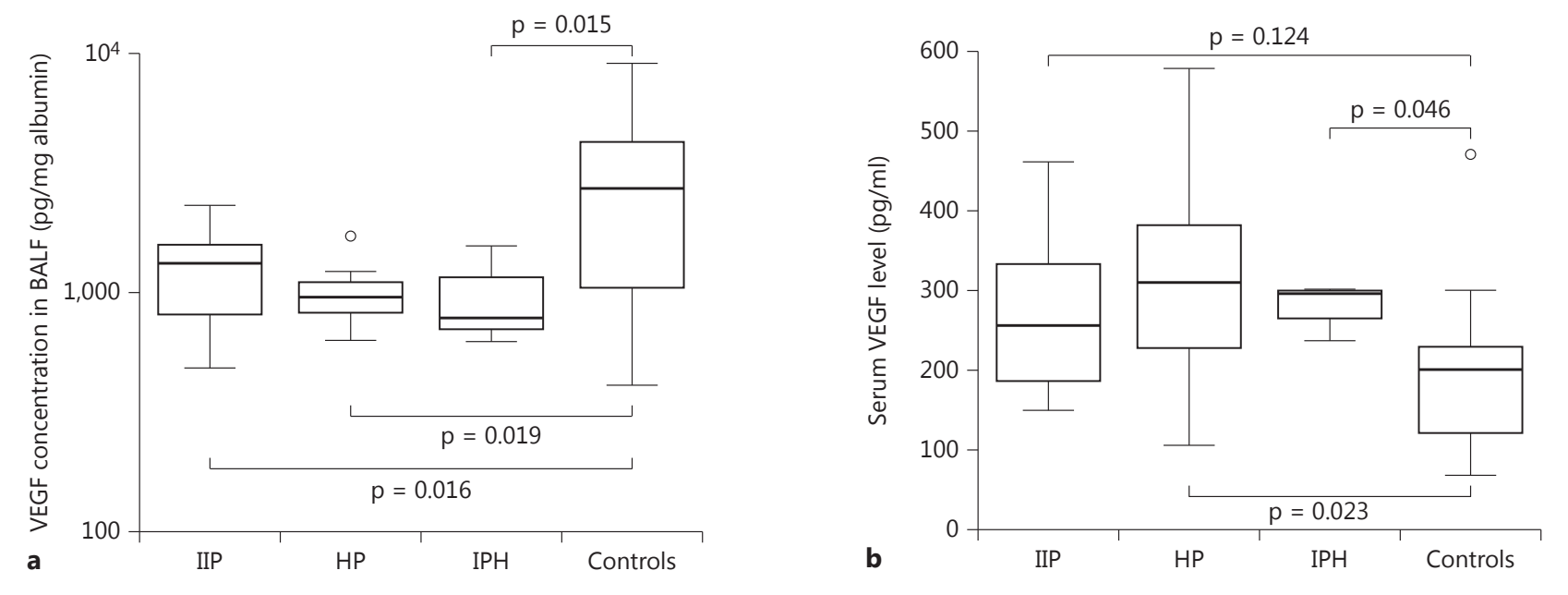

Fig. 1. VEGF/albumin ratio was measured in BALF samples (a) and VEGF concentrations in sera (b) of childhood ILD and compared to controls. VEGF/albumin in BALF was significantly decreased in all patient groups versus controls (a). In contrast, the serum VEGF level was elevated in patients versus controls, especially in HP and IPH; no significant increment was observed in IIP (b).

significant elevation in IIP (872 [220-1,476] ng/mg, $\mathrm{p}=$ 0.045 ), while no difference was observed in HP (193 [139-849] ng/mg, $\mathrm{p}=0.762)$ compared to controls (256 [178-350] ng/mg) (fig. 2).

As we supposed, VEGF/albumin and ferritin/albumin parameters might be suitable BALF biomarkers for the evaluation of intrapulmonary inflammation, therefore we analyzed the correlation of these data to some classic inflammatory markers and other functional tests by using Spearman's correlation. A significant negative correlation was found between BALF VEGF/albumin and total cell count in BALF $(\mathrm{r}=-0.411, \mathrm{p}=0.002)$ and serum CRP $(r=-0.367, p=0.006)$. In addition, the number of macrophages independently correlated with VEGF/albumin $(\mathrm{r}=-0.268, \mathrm{p}=0.049)$ (data not shown). Due to loss of compartmentalization of VEGF and its release from reactive leukocytes during the development of ILD, BALF VEGF/albumin was significantly associated with increased serum VEGF values $(\mathrm{r}=-0.371, \mathrm{p}=0.018) . \mathrm{FEV}_{1}$ values are available only in HP patients; therefore we could analyze these limited numbers of functional parameter with VEGF/albumin showing only a weak negative association $(\mathrm{r}=-0.403, \mathrm{p}=0.322)$ (data not shown). We did not show a significant relationship between VEGF/albumin and ferritin/albumin or HRCT score values of the lung either (table 3a). Ferritin/albumin was found as a less sensitive parameter in the detection of respiratory inflammation. Its association with total cell count was marginally significant

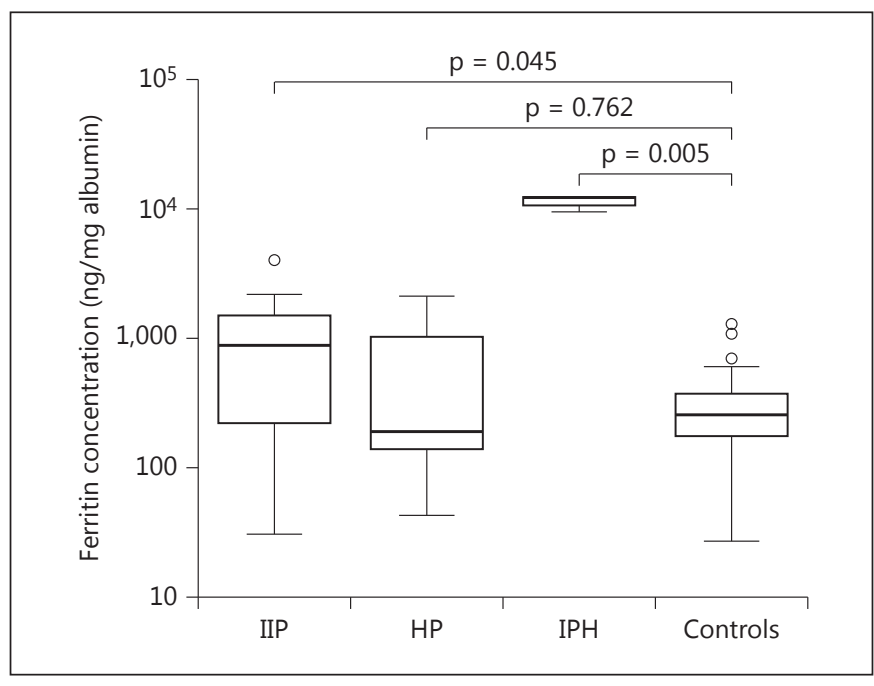

Fig. 2. Ferritin/albumin ratio in BALF samples of the ILD subgroups. We saw significantly elevated values versus controls in IIP and extremely high levels in IPH. However, in HP no difference was detected compared to controls.

$(\mathrm{r}=0.212, \mathrm{p}=0.067)$, but the macrophage count significantly correlated with ferritin/albumin ratios $(r=0.506$, $\mathrm{p}=0.002$ ). However, no additional substantial relationship was observed with other variables (table $3 b$ ). Finally, serum VEGF demonstrated a significant association with total BALF cell count $(r=0.414, p=0.010)$ (table $3 c)$. 
Table 3. Correlation between BALF VEGF/albumin ratio (a), BALF ferritin/albumin ratio (b) and serum VEGF (c) with various parameters such as laboratory and functional tests in ILD patients

\section{a Versus VEGF/albumin}

Total cell count in BALF, $\times 10^{5} / \mathrm{ml}$ Serum CRP, mg/l

Serum VEGF, pg/ml

BALF ferritin/albumin, ng/mg HRCT score

b Versus ferritin/albumin

Total cell count in BALF, $\times 10^{5} / \mathrm{ml}$

BALF macrophage count, $\times 10^{5} / \mathrm{ml}$

Serum CRP, mg/l

Serum VEGF, pg/ml

HRCT score

c Versus serum VEGF

BALF macrophage count, $\times 10^{5} / \mathrm{ml}$

Serum CRP, mg/l

BALF ferritin/albumin, ng/mg

HRCT score

${ }^{a}$ Statistically significant associations.
Total cell count in BALF, $\times 10^{5} / \mathrm{ml}$

\section{$\mathrm{p}$}

$\begin{array}{ll}-0.411 & 0.002^{\mathrm{a}} \\ -0.367 & 0.006^{\mathrm{a}} \\ -0.371 & 0.018^{\mathrm{a}} \\ -0.165 & 0.252 \\ -0.113 & 0.552\end{array}$

0.212

0.506

0.231

0.164

0.331

0.067

$0.002^{\mathrm{a}}$

0.106

0.487

0.752

0.414

$0.010^{\mathrm{a}}$

0.273

0.102

0.256

0.126

$-0.139$

0.984

0.321

\section{Discussion}

Similarly to adult patients, ILD children present a broad spectrum of relatively rare pulmonary disorders featuring persistent inflammatory injures in the lung tissue with altered fibrogenesis $[28,30,31]$. Disruption in the integrity of the alveolar epithelium occurs with the accumulation and activation of immune cells, proliferation of fibroblasts in addition to reduced apoptosis of endothelial cells and alveolar septal cells $[7,14]$. Two out of the number of proinflammatory regulators in these events are VEGF and ferritin, which increase vascular permeability and induce smooth muscle cell hypertrophy and apoptosis of epithelial cells [2,35-37]. The abnormal lung structure seems to be accompanied by the formation of new blood vessels as well. This process also requires elevated secretion of pro-angiogenic factors such as VEGF, which is chemotactic for endothelial cells and induces their von Willebrand factor and tissue factor expression $[29,38]$. Consequently, increased serum VEGF levels could be measured in serum from adults with IPF [18] and in BALF samples obtained from asthmatic [10] as well as COPD patients [39]. However, there is some evidence for a considerable shift of BALF VEGF to the cir- culation described in adults with IPF, the level of which varied with age and was significantly depressed compared to controls [14]. Similarly, significantly lower amount of VEGF was seen in ARDS individuals compared to only at-risk ARDS subjects [7, 8]. As a result, lower VEGF concentration resulted in enhanced apoptosis of vascular endothelial cells [2]. One possible explanation of controversial VEGF levels may be its analysis at different stages of inflammatory lung diseases. Both increased [18] or decreased [40] intrapulmonary levels of VEGF were associated with worse prognosis.

In our study, inflammatory cell profiles and the concentrations of VEGF, ferritin and albumin in BALF samples from 30 children with different types of ILD at various stages were compared with the data of 24 control children. A significantly increased amount of lavaged inflammatory cells was detected compared to normal conditions. In the same BALF samples, VEGF/albumin levels were significantly decreased in children with IIP, HP and IPH compared to clinical controls. Very importantly, no former data are available on BALF VEGF alteration in children with ILD. In parallel, serum VEGF levels were also analyzed in our individuals, and we found augmented serum VEGF in ILD children versus controls, as seen by Ando et al. [18], who published high serum VEGF levels in adulthood IPF, but no significant difference was shown among various ILD cohorts. A significant positive correlation was found between BALF VEGF/albumin and total cell count in BALF as well as macrophage count and serum CRP showing the presence of respiratory inflammation. However, we could not find a strong statistical relationship between BALF VEGF and HRCT score values, probably due to the relatively low number of cases. In an adult IPF group, a significant positive correlation was earlier detected between serum VEGF levels and the HRCT interstitial score $(\mathrm{p}=0.027)$ and another inflammatory marker of KL-6 levels $(\mathrm{p}=0.037)$ [18]. Furthermore, significantly depressed BALF VEGF/albumin was associated with highly increased serum VEGF values due to the loss of compartmentalization of VEGF and its release from reactive leukocytes at advancing stages of ILD, especially in our IPH subjects. On the contrary, decreased VEGF/albumin was related to moderately elevated serum VEGF in this IIP group (fig. 1a). These data suggest a distinct pathomechanism of VEGF 'leakage' - proved by an increased level of BALF albumin - from the damaged lung tissue into the circulation in the different types of ILD. Significant associations were analyzed between ferritin/albumin and serum VEGF with altered cellular content of BALF. Based on these findings, the levels of all 
these studied biomarkers followed the development of inflammatory processes in the lung already at the diagnosis of ILD. FXIIIA $A_{2}$ was under a contrary regulation, as it was elevated in BALF samples in ILD that was released from activated or injured alveolar macrophages along with an increasing amount of plasma FXIIIA ${ }_{2} B_{2}$ leaked out from the capillaries into the BALF [41].

Oxidative stress-induced angiogenesis involves VEGF signaling, but other VEGF-independent pathways are also known [42]. A number of studies suggested that an oxidant-antioxidant imbalance played a role in the progression of pulmonary fibrosis in animal models and thus in humans with IPF [43]. As a defense against oxidantmediated injury, endothelial cells up-regulate heme oxygenase- 1 and ferritin, and the latter serves as a protective antioxidant mediator [37]. On the other hand, elevated ferritin concentration in BALF has several other nonphysiological effects, including the inhibition of lymphocyte proliferation and cell growth [20], iron accumulation e.g. in cystic fibrosis [21], and increased oxidative stress in idiopathic pulmonary alveolar proteinosis [19]. Taken together, ferritin demonstrates a controversial role in inflammatory vascular disorders. Elevated serum and BALF ferritin levels were detected in injured tissues, including intestines and lung [44]. In this study, significantly higher BALF ferritin/albumin levels were measured in children with IIP and IPH, indicating severe tissue damage and inflammation. Substantially elevated BALF ferritin/ albumin in IPH indicated the development of pulmonary bleeding. However, ferritin/albumin was found to be a less sensitive parameter in the detection of respiratory inflammation, since its association was statistically significant with only macrophage count and no other substantial relationship was observed. Gono et al. [45] used serum ferritin measurement to predict the development of acute ILD as a complication of dermatomyositis. Here, we did not measure ferritin level in serum, which was considered a good marker to evaluate iron load in IPH by others [30]. To confirm the diagnostic power of these biomarkers in childhood ILD, further clinical studies are required. We presumed that BALF ferritin/albumin might be a reliable indicator of ILD processes in children, as VEGF, IL-8 and ENA-78 in BALF of adults with IPF were suggested by Vasakova et al. [46].

There are some limitations of this study. The major limitation is the relatively low number of cases. However, ILD in childhood are quite rare. Thus, differently advanced stages of ILD have to be taken into consideration when interpreting the alterations in various inflammatory mediators.

In conclusion, BALF VEGF/albumin and ferritin/albumin parameters may be considered useful biomarkers of pulmonary inflammation with BALF leakage in altered respiratory epithelium in childhood ILD. This study also provides further evidence for the usefulness of the BAL procedure for diagnostic purposes in evaluating the severity of ILD.

\section{Acknowledgements}

This study was supported by the TÁMOP-4.2.2.A-11/1/ KONV-2012-0045 project. The project was implemented through the New Hungary Development Plan, co-financed by the European Social Fund and the European Regional Development Fund. Béla Nagy Jr. was supported by the Lajos Szodoray Grant of the University of Debrecen.

\section{Financial Disclosure and Conflicts of Interest}

The authors declare that there is no conflict of interest.

\section{References}

1 Senger DR, Galli SJ, Dvorak AM, Perruzzi CA, Harvey VS, Dvorak HF, Sack U: Tumor cells secrete a vascular permeability factor that promotes accumulation of ascites fluid. Science 1983;219:983-985.

2 Koyama S, Sato E, Tsukadaira A, Haniuda M, Numanami H, Kurai M, Nagai S, Izumi T: Vascular endothelial growth factor mRNA and protein expression in airway epithelial cell lines in vitro. Eur Respir J 2002;20:14491456.

Altered Bronchoalveolar VEGF and

Ferritin in Children with ILD
-3 Martin C, Thévenot G, Danel S, Chapron J, Tazi A, Macey J, Dusser DJ, Fajac I, Burgel PR: $P$ seudomonas aeruginosa induces vascular endothelial growth factor synthesis in airway epithelium in vitro and in vivo. Eur Respir J 2011;38:939-946.

4 Monacci WT, Merrill MJ, Oldfield EH: Expression of vascular permeability factor/vascular endothelial growth factor in normal rat tissues. Am J Physiol 1993;264:C995-C1002.
5 Brown KR, England KM, Goss KL, Snyder JM, Acarregui MJ: VEGF induces airway epithelial cell proliferation in human fetal lung in vitro. Am J Physiol Lung Cell Mol Physiol 2001;281:L1001-L1010.

6 Ferrara N, Gerber HP, LeCouter J: The biology of VEGF and its receptors. Nat Med 2003; 9:669-676.

7 Mura M, dos Santos CC, Stewart D, Liu M Vascular endothelial growth factor and related molecules in acute lung injury. J Appl Physiol 2004;97:1605-1617. 
8 Thickett DR, Armstrong L, Millar AB: A role for vascular endothelial growth factor in acute and resolving lung injury. Am J Respir Crit Care Med 2002;166:1332-1337.

$\$ 9$ Meyer N, Akdis CA: Vascular endothelial growth factor as a key inducer of angiogenesis in the asthmatic airways. Curr Allergy Asthma Rep 2013;13:1-9.

10 Lee SY, Kwon S, Kim KH, Moon HS, Song JS, Park SH, Kim YK: Expression of vascular endothelial growth factor and hypoxia-inducible factor in the airway of asthmatic patients. Ann Allergy Asthma Immunol 2006;97:794799.

11 Walters EH, Soltani A, Reid DW, Ward C: Vascular remodelling in asthma. Curr Opin Allergy Clin Immunol 2008;8:39-43.

-12 Nishigaki Y, Fujiuchi S, Yamazaki Y, Matsumoto H, Takeda A, Fujita Y, Okamoto K, Fujikane T, Shimizu T, Kikuchi K: Increased vascular endothelial growth factor in acute eosinophilic pneumonia. Eur Respir J 2003 21:774-778.

-13 Lee SH, Lee SH, Kim CH, Yang KS, Lee EJ, Min KH, Hur GY, Lee SH, Lee SY, Kim JH, Shin C, Shim JJ, In KH, Kang KH, Lee SY: Increased expression of vascular endothelial growth factor and hypoxia inducible factor$1 \alpha$ in lung tissue of patients with chronic bronchitis. Clin Biochem 2014;47:552-559.

- 14 Meyer KC, Cardoni A, Xiang ZZ: Vascular endothelial growth factor in bronchoalveolar lavage from normal subjects and patients with diffuse parenchymal lung disease. J Lab Clin Med 2000;135:332-338.

-15 Koyama S, Sato E, Haniuda M, Numanami H, Nagai S, Izumi T: Decreased level of vascular endothelial growth factor in bronchoalveolar lavage fluid of normal smokers and patients with pulmonary fibrosis. Am J Respir Crit Care Med 2002;166:382-385.

- 16 Cosgrove GP, Brown KK, Schiemann WP, Serls AE, Parr JE, Geraci MW, Schwarz MI, Cool CD, Worthen GS: Pigment epitheliumderived factor in idiopathic pulmonary fibrosis: a role in aberrant angiogenesis. Am J Respir Crit Care Med 2004;170:242-251.

17 Borensztajn K, Crestani B, Kolb M: Idiopathic pulmonary fibrosis: from epithelial injury to biomarkers - insights from the bench side. Respiration 2013;86:441-452.

$\checkmark 18$ Ando M, Miyazaki E, Ito T, Hiroshige S, Nureki SI, Ueno T, Takenaka R, Fukami T, Kumamoto T: Significance of serum vascular endothelial growth factor level in patients with idiopathic pulmonary fibrosis. Lung 2010 188:247-252.

19 Ghio AJ, Stonehuerner JG, Richards JH, Crissman KM, Roggli VL, Piantadosi CA, Carraway MS: Iron homeostasis and oxidative stress in idiopathic pulmonary alveolar proteinosis: a case-control study. Respir Res 2008;9:10.

20 Stites SW, Plautz MW, Bailey K, O'Brien-Ladner AR, Wesselius LJ: Increased concentrations of iron and isoferritins in the lower re- spiratory tract of patients with stable cystic fibrosis. Am J Respir Crit Care Med 1999;160: 796-801.

21 Ghio AJ, Roggli VL, Soukup JM, Richards JH, Randell SH, Muhlebach MS: Iron accumulates in the lavage and explanted lungs of cystic fibrosis patients. J Cyst Fibros 2013;12: 390-398.

22 Shannahan J, Schladweiler M, Padilla-Carlin D, Nyska A, Richards J, Ghio A, Gavett S, Kodavanti U: The role of cardiovascular diseaseassociated iron overload in Libby amphiboleinduced acute pulmonary injury and inflammation. Inhal Toxicol 2011;23:129-141.

23 Smith JJ, O’Brien-Ladner AR, Kaiser CR, Wesselius LJ: Effects of hypoxia and nitric oxide on ferritin content of alveolar cells. J Lab Clin Med 2003;141:309-317.

24 Wells AU: The clinical utility of bronchoalveolar lavage in diffuse parenchymal lung disease. Eur Respir Rev 2010;19:237-241.

25 Capelozzi VL, Faludi EP, Balthazar AB, Fernezlian Sde M, Filho JV, Parra ER: Bronchoalveolar lavage improves diagnostic accuracy in patients with diffuse lung disease. Diagn $\mathrm{Cy}$ topathol 2013;41:1-8.

26 Nagy B, Katona E, Erdei J, Székely E, Márialigeti T, Karmazsin L, Fachet J: Fibronectin in bronchoalveolar lavage fluid and plasma from children with chronic inflammation of lungs. Acta Paediatr Scand 1988;77:727-733.

27 Gupta S, Smith P, Twigg HL III, Hage CA: Bronchoalveolar lavage cellular patterns in monoclonal antibody-induced lung disease. Respiration 2014;88:185-189.

28 Meyer KC, Raghu G, Baughman RP, Brown KK, Costabel U, du Bois RM, Drent M, Haslam PL, Kim DS, Nagai S, Rottoli P, Saltini C, Selman M, Strange C, Wood B; American Thoracic Society Committee on BAL in Interstitial Lung Disease: An official American Thoracic Society clinical practice guideline: the clinical utility of bronchoalveolar lavage cellular analysis in interstitial lung disease. Am J Respir Crit Care Med 2012;185:1004-1014.

29 Galuska L, Márton H, Szanyi A, Nagy B: The role and prognostic value of $99 \mathrm{~m}$ technetium diethylene triamine penta acetic acid aerosol in lung clearance of children with allergic alveolitis. Int Rev Allergol Clin Immunol 2000; 6:64-69.

30 Clement A; ERS Task Force: Task force on chronic interstitial lung disease in immunocompetent children. Eur Respir J 2004;24: 686-697.

31 Clement A, Eber E: Interstitial lung diseases in infants and children. Eur Respir J 2008;31: 658-666.

32 Priftis KN, Anthracopoulos MB, Tsakanika C, Tapaki G, Ladis V, Bush A, Nicolaidou P: Quantification of siderophages in bronchoalveolar fluid in transfusional and primary pulmonary hemosiderosis. Pediatr Pulmonol 2006:41:972-977.

33 Baktai G, Péterffy E, Székely E, Tiszlavicz L, Nagy B, László A: Leading pulmonary symp- toms in an infant with Niemann-Pick disease (abstract). Eur Respir J 2001;18(suppl 33): S220.

34 Nagy B, Soós G, Nagy K, Dezső B: Natural course of isolated pulmonary Langerhans cell histiocytosis in a toddler. Respiration 2008; 75:215-220.

-35 Gross TJ, Hunninghake GW: Idiopathic pulmonary fibrosis. N Engl J Med 2001;345:517525 .

36 Selman M, Pardo A: Revealing the pathogenic and aging-related mechanisms of the enigmatic idiopathic pulmonary fibrosis. An integral model. Am J Respir Crit Care Med 2014; 189:1161-1172.

37 Balla J, Vercellotti GM, Jeney V, Yachie A, Varga Z, Eaton JW, Balla G: Heme, heme oxygenase and ferritin in vascular endothelial cell injury. Mol Nutr Food Res 2005;49:10301043.

38 Takahashi M, Kunugi S, Terasaki Y, Terasaki M, Urushiyama H, Kuwahara N, Wakamatsu K, Nakayama T, Fukuda Y: The difference of neovascularization in early intra-alveolar fibrosis between nonspecific interstitial pneumonia and usual interstitial pneumonia. Pathol Int 2013;63:237-244.

39 Lee CG, Ma B, Takyar S, Ahangari F, Delacruz $\mathrm{C}, \mathrm{He} \mathrm{CH}$, Elias JA: Studies of vascular endothelial growth factor in asthma and chronic obstructive pulmonary disease. Proc Am Thorac Soc 2011;8:512-515.

40 Maitre B, Boussat S, Jean D, Gouge M, Brochard L, Housset B, Adnot S, Delclaux C: Vascular endothelial growth factor synthesis in the acute phase of experimental and clinical lung injury. Eur Respir J 2001;18:100-106.

41 Katona E, Nagy B, Kappelmayer J, Baktai G, Kovács L, Márialigeti T, Dezső B, Muszbek L: Factor XIII in bronchoalveolar lavage fluid from children with chronic bronchoalveolar inflammation. J Thromb Haemost 2005;3: 1407-1413.

42 Kim YW, Byzova TV: Oxidative stress in angiogenesis and vascular disease. Blood 2014; 123:625-631.

43 Kinnula VL, Myllärniemi M: Oxidant-antioxidant imbalance as a potential contributor to the progression of human pulmonary fibrosis. Antioxid Redox Signal 2008;10:727-738.

44 Park YY: Ischemia/reperfusion lung injury increases serum ferritin and heme oxygenase-1 in rats. Korean J Physiol Pharmacol 2009;13:181-187.

45 Gono T, Kawaguchi Y, Hara M, Masuda I, Katsumata Y, Shinozaki M, Ota Y, Ozeki E, Yamanaka H: Increased ferritin predicts development and severity of acute interstitial lung disease as a complication of dermatomyositis. Rheumatology 2010;49:1354-1360.

46 Vasakova M, Sterclova M, Kolesar L, Slavcev A, Pohunek P, Sulc J, Skibova J, Striz I: Bronchoalveolar lavage fluid cellular characteristics, functional parameters and cytokine and chemokine levels in interstitial lung diseases. Scand J Immunol 2009;69:268-274. 